Journal of Education and Educational Development

8(2), 255-269, 2021

DOI: http://dx.doi.org/10.22555/joeed.v8i2.456

\title{
Take a Public Speaking Course and Conquer the Fear
}

\author{
Karen Kangas Dwyer \\ University of Nebraska-Omaha, United States \\ Marlina Davidson \\ University of Nebraska-Omaha, United States
}

\begin{abstract}
The purpose of this research project was to investigate if students today still report a fear of public speaking more often than death and if after completing a public speaking course, their fears change. Participants in a multi-section public speaking course $(N=374)$ completed a pre-and post-course survey asking them to select their fears and also complete public speaking anxiety questions. The results showed that pre-course public speaking was chosen more often than death and all other fears except for family tragedy, but after completing the course, the fear of public speaking was no longer selected more than death and was not even among the top five fears students listed. The findings help clarify the important impact a public speaking class has on students'fears. The review of literature addresses why students should enroll in a basic public speaking course and conquer their fear or anxiety about public speaking while still in college. The discussion focuses on how public speaking instructors can help students conquer their fear.
\end{abstract}

Keywords: communication, fears, general education, introductory communication course, public speaking anxiety

\section{Introduction}

College students often find public speaking to be too humiliating or too demanding, and they do not want to waste their time taking a speech class. Students have even started condemning in-class presentations, suggesting they are unfair to those with fear and anxiety of speaking in public, and calling for institutions to offer alternative options (Lorenz, 2017). Thus, a speech class is not a student's 
favorite experience in college or the first choice for their schedule. So, the question often asked by students is, "Why should I take a public speaking course?"

Generation Z (born after 2000) report they are not prepared to speak confidently to a large group of people (Workforce Institute at Kronos, 2019). One poll showed that 74\% of Gen Z's report a fear of public speaking (Motavalli, 2015), while others report a higher percentage of public speaking fear in college students especially in women (Sugiyati \& Indriani, 2021). The fear of public speaking tends to turn away from opportunities to develop their public speaking skills. One reason why college students may not value a public speaking course is the growth of technological advances in communication including social media that enable students to voice their opinion without speaking face-to-face. This dependence on technology is happening at a time when some in higher education are recommending cuts in many of the required general education classes, even up to half of the courses (Marquez, 2017).

Those who want to cut general education courses point out reasons such as a) the higher cost of education per credit hour and therefore, a reduction in course equals a reduction in tuition, b) changes in values reinforcing a career focus instead of the traditional focus where all students take a basic liberal arts education, c) the dislike for general education courses that many students call a 'waste of time' and d) the belief by students that general education courses are 'GPA killers' because they often receive lower grades in these courses (Jordan, 2017). One research organization even reported that $30 \%$ of all higher-level institutions do not offer oral communication skills as a part of their general education course requirements and more institutions are choosing to eliminate communication requirements (The Hart Research Associates, 2016).

The university introductory public speaking course has always been the main course that fosters public speaking competence and is often part of the general education curriculum. One recent survey focusing on university introductory communication courses showed that when a communication course is required for general education in the United States, almost $88 \%$ of the course is oriented to public speaking and most of these courses help students overcome the fear or anxiety about public speaking (Morreale et al., 2016). However, with cuts in general education, that is changing too. 
Historically, the interest in surveying public speaking as a top fear dates back to October 7, 1973, when the London Sunday Times reported that the largest number of Americans, 41\% of those surveyed by R. H. Bruskin Associates listed speaking before a group as their greatest fear (Bruskin Report, 1973; Speech Communication Association, 1973). This report was quoted in many public speaking textbooks and by numerous speech teachers, authors, and consultants. In 2012, Dwyer and Davidson investigated the genesis of the Bruskin Fears study and replicated it with college students. They reported that pre-course public speaking students selected public speaking from the same list of 14 fears more often than any other fear, including death. Dwyer and Davidson (2012) called for additional research using an updated list of fears as well as investigating if students' common fears change after completing a public speaking class. As part of a yearly university assessment of the required general education public speaking course, this present study using an updated list of 40 common fears, investigated if college students report a fear of public speaking more than death and if, after completing a public speaking course their fears and anxieties change.

\section{Literature Review}

\section{Public Speaking Anxiety}

The fear of public speaking in communication research has been defined as specific communication-based anxiety in which individuals experience physiological arousal, negative cognitions, and/or behavioral responses to real or anticipated presentations (Ayres \& Hopf, 1989). In psychological research, public speaking anxiety (PSA) has been classified as social anxiety with a "threat of unsatisfactory evaluations from audiences" (Schlenker \& Leary, 1982, p. 646). High PSA has been associated with poor preparation, poor speech decision-making, and negative affect and effect on performance. Some have classified the fear of public speaking as a social phobia, because of its intensity and importance in a person's life (Doctor, 2008).

PSA is very different from high trait or overall communication apprehension, often researched under the term 'common biological perspective' (McCroskey \& Beatty, 2000). Sometimes, this term has mistakenly been applied to those who simply need extra help in overcoming a fear or anxiety about communication. The common biological perspective focuses on neurological system processing 
and cerebral functioning related to neurotic introverts who represent a smaller percentage of people that cannot easily overcome fears or anxieties. On the other hand, studies focused on anxiety in the public speaking context report that PSA is common and that approximately 60 to $75 \%$ of individuals and college students report experiencing PSA (Dwyer \& Davidson, 2012; Richmond et al., 2013).

Over the last several decades, research has established the relationship between communication anxieties and retention or academic success in college (Brandão et al., 2017). For example, students with higher levels of communication anxiety are more likely to drop out of college and have lower GPA's (McCroskey et al., 1989), and freshman or sophomores either became less apprehensive about communication by their junior year or do not graduate (Rubin et al., 1990).

PSA is unrelated to intelligence, but it does keep students from attaining their goals and graduating from college (Brandão, 2017). However, this does not have to be the case. Public speaking is a teachable skill and when students are given the instruction and assistance in a general education public speaking course, students can overcome their anxiety and learn effective communication skills. For public speaking instructors, the topic of speech anxiety and the fear of public speaking is usually mentioned in their chosen textbooks and their classes.

\section{Fears Studies}

In 1973, the Bruskin Fears survey reported that people selected public speaking as a fear more often than they selected death. Their report became so popularized that textbooks cited it and continue to mention the fear of public speaking as a common fear (e.g., Beebe \& Beebe, 2015). In 1993, Bruskin-Goldrig Research, Inc., of Edison, N.J. published another survey report in which they asked 1,000 Americans to select the things that they considered nightmares or terrors. Forty-five percent of the participants (54\% of the women, $34 \%$ of the men) selected speaking before a group as a terror, followed by financial problems (40\%) and fear of heights (40\%) (Quirks, 1993).

In 2001, Gallup collected data on American fears from 1,016 adults, 18 years and older using a phone survey that invited participants to select from a list of fears that they might fear. The Gallup News Service Report, entitled Snakes Top List of Americans' Fears, author Geoffrey Brewer (2001) reported: "More people -- 
$51 \%$-- fear snakes than any other suggested possibility, including speaking in front of an audience (40\%) and heights (36\%)" (para. 2). Brewer (2001) further reported that adults seemed slightly less fearful of some things in 2001 than in the previous Gallup 1998 fears survey. A chart comparing the 2001 results to the 1998 results included $(2001,1998)$ : Snakes $(51 \%, 56 \%)$ then public speaking $(40 \%, 45 \%)$. The Gallup poll reported those with less education were more likely to be afraid to speak in front of an audience than those with more education (52\% of those with a high school education or less fear speaking in public, compared to only $24 \%$ of college graduates; Brewer, 2001).

This study used a current list of general fears. Future researchers should add other fears related to the changes in culture and evolving generational concerns of incoming students. For example, the fears used in this study did not include political or geographical fears which were beyond the focus of this study. However, a recent research report of what Americans feared in 2019 includes these top 10 fears: (1) corrupt government officials (2) pollution in the oceans rivers, and lakes, (3) people I love becoming seriously ill (4) Pollution of drinking water (5) people I love dying (6) air pollution (7) cyber-terrorism (8) extinction of plant and animal species (9) global warming and climate change and (10) not having enough money for the future (Sheth, 2019). This same organization queried Americans' fears a few years earlier and found the fears ranked this way: (1) public speaking (2) heights (3) bugs, snakes (4) drowning (5) blood/needles (6) claustrophobia (7) flying (8) strangers (9) zombies (10) darkness (11) clowns (12) ghosts (Chapman University, 2014). This could mean that fears are changing for Americans or it could mean that public speaking was not on their minds. One of the sociologists involved in the earlier study suggested that fears are linked to television watching (Bader, 2014). The more people watch television, it seems that their fears change and align with what they watch. This could explain the differences reported in the 2014 fears study versus the 2019 study when Americans' fears centered more on political officials and climate. These findings indicate that future researchers should include the changing mores and fears in their research questions and data collection methodologies.

As discussed earlier, Dwyer and Davidson (2012) replicated the Bruskin survey (Watson, 1973) and reported that college pre-course public speaking students selected the fear of public speaking more often than death. They called for additional research using an updated list of common fears to investigate if students' 
fears change after completing a general education public speaking course. With an updated fears list, the study could be an extension of the often-quoted Bruskin Fears Study on a current population.

Therefore, the purpose of this assessment study was to follow the recommendations of the Bruskin survey replication (Dwyer \& Davidson, 2012) and investigate pre-course public speaking students' selection of fears using an updated list of 40 common fears, as well as their changes in anxiety levels after completing the class.

\section{Research Questions}

1. Will pre-course and post-course students select speaking in public among their common fears more often than they select death when choosing from a current list of 40 common fears?

2. How does the occurrence of a reported 'fear' of public speaking compare between pre-course and post-course students?

3. How do PSA scores change from pre-course to post-course?

4. For pre-course and post-course students, how do PSA scores compare between students who fear public speaking and those who do not?

\section{Methodology}

\section{Participants}

Participants in this study included 374 college students enrolled in 35 sections of a face-to-face public speaking course which fulfills the required public speaking general education requirement at a large Midwestern university, including 168 (44.9\%) male, 205 (54.8\%) female, and 1 (.3\%) unknown. The course used a standard syllabus, textbook, workbook, exams, and requirement of four formal speeches. In addition, all instructors devoted at least one class period to demonstrating simple anxiety management strategies, such as breathing techniques, relaxation methods, and positive coping processes that can help students ease their feelings of discomfort. Respondents represented a cross-section of class rankings: 231 (61.8\%) freshmen, 84 (22.5\%) sophomores, 39 (10.4\%) juniors, 19 (5.1\%) seniors, and $1(3 \%)$ unknown. 


\section{Procedure and Instrument}

Data was collected from pre-and post-course public speaking students as part of the general education oral communication assessment procedures. Students were asked two questions in addition to demographic questions. The first question began by stating, 'Everybody has fears about some things. Please check all the things on this shortlist that make you fearful or anxious' (see Table 1 for a list of common fears). The list of forty fears was based on the R. H. Bruskin and Associates fears list as cited in Spectra (Speech Communication Association, 1973) plus 26 additional common fears listed in more recent fears studies (Muris et al., 1997; Seim \& Spates, 2010). The second question included the PRCA-24 (Bodie, 2010) six public speaking context scale items. The six items were chosen because of the brevity and focus on public speaking anxiety as well as the established use of the instrument in assessing communication apprehension in contexts, such as public speaking (McCroskey, 1982b). The six-item scale generally produces reliability estimates in the range of .80 to .88 , with demonstrated construct, concurrent, discriminant, and predictive validity (Levine \& McCroskey, 1990). The obtained reliability coefficients (Cronbach's alpha) for this study were .89 (pre-course) and .85 (post-course). The authors of this report downloaded, removed all identifiers, and tabulated results for assessment purposes.

\section{Findings}

Research question one explored how the selection of the fear of public speaking compared to the selection of the fear of death for pre-course and postcourse students. Although data showed that pre-course public speaking students chose to speak before a group $(\mathrm{N}=179)$ more often than they chose death $(\mathrm{N}$ =160), a McNemar's chi-square for binomial distribution was employed to test consistency in responses across two variables and calculated comparing the frequency of students selecting the fear of public speaking and the fear of death. The McNemar test is used to examine paired dichotomous data. More specifically, the test is a ratio of the squared difference in discordant frequencies relative to the total discordant frequencies (Bellack \& Hersen, 1998).

The results showed that for pre-course students, there was no significant interaction found and the two fears occurred at the same rate, $p=.148$. Thus, public speaking and death were both highly chosen but not significantly different when 
pre-course public speaking students were asked to select their fears from a list of 40 common fears (see Table 1). Results also showed that for post-course students, a significant interaction was found, and the two fears did not occur at the same rate, $\mathrm{p}=.0015$. Thus, when the same public speaking students were asked postcourse to select their fears from the same list, students chose death $(\mathrm{N}=170)$ more often than they chose public speaking $(\mathrm{N}=129)$. Table 1 shows the results of the students' 40 fears and compares them to those listed by the popular 1973 Bruskin study (Watson, 1973).

Research question two explored if there was a difference between precourse and post-course students in the prevalence of fear of public speaking. Again, a McNemar's chi-square for testing consistency in responses across two variables was calculated comparing the frequency of students selecting the fear of public speaking pre-course and post-course. A significant interaction was found, and we can conclude that the fear of public speaking occurs at different rates for pre-course $(\mathrm{N}=179)$ and post-course students $(\mathrm{N}=129)$.

To answer research question three, a paired sample t-test was calculated to determine if there was a difference between the mean anxiety score for students' pre-course and post-course, and results indicated a significant difference between the two scores pre-course and post-course. On average, students' anxiety changes scores dropped significantly from pre-course to post-course $(\mathrm{M}=2.00, \mathrm{SD}=4.55)$.

Finally, to answer research question four, an independent sample t-test was calculated for students who reported a fear of public pre-course to determine how public speaking anxiety (PSA) change scores compared between students who did not report public speaking as a fear post-course $(\mathrm{N}=73)$ and those who $\operatorname{did} \operatorname{not}(\mathrm{N}=$ 101). The variances were sufficiently equal, so the Pooled tests were used. Results indicate a significant difference between the PSA change score for students who did not fear public speaking $(\mathrm{M}=-4.23, \mathrm{SD}=4.50)$ and the PSA change score for students who did $(\mathrm{M}=-1.85, \mathrm{SD}=4.83)$ at the end of the course, $\mathrm{t}(172)=-3.30$, $\mathrm{p}=.001$. That is, for students who feared public speaking pre-course, there was a significant difference in the anxiety change scores of students who still feared public speaking post-course and those who did not. 


\section{Discussion}

A wide range of communication skills has been referenced by both professionals and academics as important for the development of communication competence. Helping students overcome situational and context public speaking anxiety has been well researched in the communication field (Dwyer, 2000; Hunter et al., 2014). What had not been studied as extensively is how a general education public speaking course can impact students' pre to post fear selections, especially for those who report public speaking among their highest fears. In this study, we found that before taking a general education public speaking course, the students' selection of public speaking and death were not significantly different both were among the top five fears selected. After completing a public speaking course, students selected death more often than public speaking death and family tragedy were the top two fears and public speaking was no longer among the top five fears selected.

It has been estimated that up to $75 \%$ of students report a fear of public speaking (Dwyer \& Davidson, 2012; Motavalli, 2015). This study found that before taking a public speaking course, almost $50 \%$ of all students selected public speaking as a fear. However, post-course that percentage dropped significantly. It appears that completing a general education public speaking course can make a difference in what students fear. This study, as well as others, has found that a public speaking course can significantly help reduce public speaking fear and anxiety for students.

There is still evidence that shows some general education courses just cannot be eliminated. Among those classes, an introductory public speaking class needs more attention than ever. Individuals who have completed a university general education public speaking course have reported increased competence and confidence in general and especially in public speaking (Weismann et al., 2018). So, why would higher education suggest eliminating a general education public speaking course at a time when students need more competence and confidence and reduced fear of public speaking?

Anxiety in college is very common and seems to be increasing every year (Conley et al., 2020). In Fall, 2018, the American College Health Association reported that $63 \%$ of college students in the United States felt overwhelming anxiety during the year. Other studies have shown that general anxiety contributes 
to increased public speaking anxiety and tension (Sutarsyah, 2017). Anxiety in general and public speaking anxiety or fear is not going away for college students.

The types of fear that students experience about public speaking have been studied and consistently reveal specific categories of internal and external fears (Dwyer, 2021; LeFebvre, et. al, 2018). The general categories, for example, include: audience responses (e.g., feeling judged by others or that others will be bored), inability to self-regulate (e.g., memory losses or forgetfulness, poor eye contact) disfluency (e.g., using too many fillers such as 'uhms'), performance evaluation (e.g., feeling they will not make a good grade), excessive activation (e.g., shakiness, nervousness, panic attacks), ineffective nonverbal vocal delivery (e.g., speaking too quickly or with too high of volume), unpreparedness (e.g., never feeling any preparation is enough), insufficient audience analysis (e.g., not knowing what the audience would find interesting or favorable), misaligned information (e.g., being able to provide accurate and trustworthy information), inadequate public speaking skills (e.g., lack of experience or training), distracting nonverbal physical delivery (e.g., swaying or wringing hands), and other unexpected events (e.g., falling in front of class or slide show malfunction) (LeFebvre, et. al, 2018). The only way for students to overcome these specific public speaking fears is to take an introductory public speaking class, where college professors are trained to help students learn the skills, gain confidence and overcome the public speaking fear and anxiety.

\section{Conclusion and Recommendations}

Future studies should consider expanding this study to multiple universities and incorporate a longitudinal component, keeping track of students throughout their college tenure to see how student fears, especially the fear of public speaking, change over time. Future studies comparing students, who are required to take, who choose to take, and who do not take a public speaking course should be undertaken to help shed light on how the course impacts student communication fears. The population for such studies should be expanded to international universities so many more student fears and college speech requirements could be queried.

This study found completing a public speaking course can make a difference in what students fear. Despite the limitations that the data was collected from one multi-section introductory public speaking course at one large university over one year, this study provides additional support that taking a general education 
public speaking course makes a difference in students' lives. It adds to the research that shows students gain competence and confidence in the course as well as fear reductions.

Graduates and employers alike report that developing effective presentation skills is an important job-related skill. Alumni who completed a public speaking course report higher levels of confidence across 12 aspects of business presentations as compared to alumni who did not take a course focused on presentations (Marcel, 2015). Given that public speaking is more important today than ever, it doesn't make sense to reduce the time students spend devoted to improving their public speaking skills or even eliminate the general education requirement. This study provides support that taking a public speaking course, especially the general education introductory course required by universities can make a difference in students' lives. So, when students ask, why should they take a public speaking class; the reply is because overcoming the fear or anxiety of public speaking and gaining confidence as well as competence for speaking in front of others will help develop your ability to succeed in many areas and become integrated into the job market!.

\section{References}

American College Health Association (2018). American College Health AssociationNational College Health Assessment II: Undergraduate Student Reference Group Data Report Fall 2018. Silver Spring, MD: American College Health Association, 2018. https://www.acha.org/documents/ncha/NCHAII_Fall_2018_ Undergraduate_Reference_Group_Data_Report.pdf

Ayres, J., \& Hopf, T. (1989). Visualization: Is it more than extra-attention? Communication Education, 38, 1-5. https://doi.org/10.1080/03634528909378735

Bader, C. (2014). Bader, C. D., Day, L. E., \& Gordon, A. (2021, May 3). Chapman Survey of American Fears, Wave 1. https//: doi: 10.17605/osf.io/vf7tn

Beebe, S. A., \& Beebe, S. J. (2015). Public speaking: An audience-centered approach. (9th Ed.). Pearson Education.

Bellack, A. S., \& Hersen, M., (1998). Comprehensive clinical psychology. Amsterdam, New York: Pergamon. p. 276.

Bodie, G. D. (2010). A racing heart, rattling knees, and ruminative thoughts: Defining, explaining, and treating public speaking anxiety. Communication Education, 59, 70-105. https://doi.org/10.1080/03634520903443849 
Brandão, A. S., Bolsoni-Silva, A. T., \& Loureiro, S. R. (2017). The predictors of graduation: Social skills, mental health, academic characteristics. Paidéia (Ribeirão Preto), 27(66), 117-125. https://www.scielo.br/pdf/paideia/v27n66/0103-863Xpaideia-27-66-00117.pdf

Brewer, G. (2001, March 19). Snakes top list of Americans'fears: Public speaking, heights and being closed in small spaces also create fear in many Americans. Gallup.

Bruskin Report (1973, July). What are Americans afraid of? (Research Rep. No. 53). Chapman University. (2014, October 21). Survey shows what Americans fear most. Science Daily. Retrieved March 15, 2021 from www.sciencedaily.com/ releases/2014/10/141021125937.html

Conley, C. S., Shapiro, J. B., Huguenel, B. M., \& Kirsch, A. C. (2020). Navigating the college years: Developmental trajectories and gender differences in psychological functioning, cognitive-affective strategies, and social well-being. Emerging Adulthood, 8(2), 103-117. https://doi.org/10.1177/2167696818791603

Doctor, R. M., Kahn, A. P., \& Adamec, C. A. (2008). The encyclopedia of phobias, fears, and anxieties. New York: Facts on File.

Dwyer, K. (2000). The multidimensional model: Teaching students to self-manage high communication apprehension by self-selecting treatments. Communication Education, 49, 72-81. https://doi.org/10.1080/03634520009379194

Dwyer, K. (2021). Iconquer speech anxiety workbook. KLD Books.

Dwyer, K. K., \& Davidson, M. M. (2012). Is public speaking really more feared than death? Communication Research Reports, 29(2), 99-107.

Finn, A. N., Sawyer, C. R., \& Schrodt, P. (2009). Examining the effect of exposure therapy on public speaking state anxiety. Communication Education, 58, 92-109. https:// doi.org/10.1080/03634520802450549

Hinojo-Lucena, F. J., Aznar-Díaz, I., Cáceres-Reche, M. P., Trujillo-Torres, J. M., \& Romero-Rodríguez, J. M. (2020). Virtual reality treatment for public speaking anxiety in students. Advancements and results in personalized medicine. Journal of Personalized Medicine, 10(1), 14. https://doi.org/10.3390/jpm10010014

Howe, M. M., \& Dwyer, K. K. (2007). The influence of diaphragmatic breathing to reduce situational anxiety for basic course students. Basic Communication Course Annual 19(9), 104-137. https://pdfs.semanticscholar.org/0fdd/ b012ac68224b3992a365cfb0b5deea1332bd.pdf

Hart Research Associates. (2016). Recent trends in general education design, learning outcomes, and teaching approached. https://www.aacu.org/sites/default/files/files/ LEAP/2015_Survey_Report2_GEtrends.pdf 
Hunter, K. M., Westwick, J. N., \& Haleta, L. L. (2014). Assessing success: The impacts of a fundamentals of speech course on decreasing public speaking anxiety. Communication Education, 63(2), 124-135. https://doi.org/10.1080/03634523.20 13.875213

Jordan, M. (2017, October 13). Opinion: Colleges need to cut down on general education requirements. The Reveille. http://www.lsunow.com/daily/opinion-colleges-needto-cut-down-on-general-education-requirements/article_e7981ac4-aeb8-11e7b17a-0ba5075ca9b4.html

Kelly, L., \& Keaten, J. (2009). Skills Training as a treatment for communication Problems. In J. A. Daly, J. C. McCroskey, J. Ayres, T. Hopf, D. Sonandre, \& T. A. Wongprasert (Eds.), Avoiding communication: Shyness, reticence, and communication apprehension (pp. 293--326). Hampton Press.

LeFebvre, L., LeFebvre, L. E., \& Allen, M. (2018). Training the butterflies to fly in formation: Cataloguing student fears about public speaking. Communication Education, 67(3), 348-362. https://doi.org/10.1080/03634523.2018.1468915

Levine, T. R., \& McCroskey, J. C. (1990). Measuring trait communication apprehension: A test of rival measurement models of the PRCA-24. Communications Monographs, 57, 62-72. https://doi.org/10.1080/03637759009376185

Lorenz, T. (2018, September 12). Teens Are Protesting In-Class Presentations. The Atlantic, http://https://www.theatlantic.com/education/archive/2018/09/teens-think-theyshouldnt-have-to-speak-in-front-of-the-class/570061/

Marcel, M. (2015). What's the best course? Evidence from alumni on the value of business presentations preparation. Journal of Education for Business, 90(1), 10-17. https:// doi.org/10.1080/08832323.2014.968515

Marquez, C. (2017, April 28). Fewer general education courses eyed in 2018.

The Varsitarian, http://varsitarian.net/special-reports/20170428/fewer-general education-course seyed-in-2018

McCroskey, J. C. (1982b). An introduction to rhetorical communication (4th ed.). Englewood Prentice-Hall.

McCroskey, J. C., \& Beatty, M. J. (2000). The communibiological perspective: Implications for communication in instruction. Communication Education, 49, 1-6. https://doi. org/10.1080/03634520009379187

Morreale, S. P., Myers, S. A., Backlund, P. M., \& Simonds, C. J. (2016). Study IX of the basic communication course at two-and four-year US Colleges and Universities: a re-examination of our discipline's "front porch". Communication Education, 65(3), 338-355. http://dx.doi.org/10.1080/03634523.2015.1073339 
Motavalli, J. (2015, June 25). Millennials and Gen Z fear other drivers more than death, public speaking and spiders. Mother Nature Network. Retrieved from https://www.

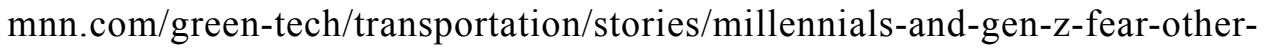
drivers-more-death-public-speaking-and-spiders

Muris, P., Merckelbach, H., \& Collaris, R. (1997). Common childhood fears and their origins. Behavior Research and Therapy, 35(10), 929-937. https://doi.org/10.1016/ S0005-7967(97)00050-8

Quirks Marketing Research Media. (1993, March). Nightmare on main street—Americans biggest fears. Retrieved from http://www.quirks.com/articles/a1993/19930407. aspx

Richmond, V., \& McCroskey, J. C. (1998). Communication: Apprehension, avoidance, and effectiveness (4th ed.). Gorsuch Scarisbrick.

Rubin, R. B., Graham, E. E., \& Mignery, J. T. (1990). A longitudinal study of college students' communication competence. Communication Education, 39, 1-14. https://doi.org/10.1080/03634529009378783

Schlenker, B. R., \& Leary, M. R. (1982). Social anxiety and self-presentation: A conceptualization model. Psychological Bulletin, 92(3), 641. https://doi. org/10.1037//0033-2909.92.3.641

Seim, R. W., \& Spates, C. R. (2010). The prevalence and comorbidity of specific phobias in college students and their interest in receiving treatment. Journal of College Student Psychotherapy, 24, 49-58. https://doi.org/10.1080/87568220903400302

Shi, X., Brinthaupt, T. M., \& McCree, M. (2015). The relationship of self-talk frequency to communication apprehension and public speaking anxiety. Personality and Individual Differences, 75, 125-129. https://doi.org/10.1016/j.paid.2014.11.023

Sheth, S., (2019). America's Top Fears 2019. Chapman University https://www.chapman. edu/wilkinson/research-centers/babbie-center/_files/americas-top-fears-2019.pdf

Speech Communication Association. (1973, December). Fears. Spectra, 9(6), p. 4.

Sugiyati, K., \& Indriani, L. (2021). Exploring the level and primary causes of public speaking anxiety among English department students. Journal of Research on Language Education, 2(1), 57-66. https://ejurnal.teknokrat.ac.id/index.php/JoRLE/index

Sutarsyah, C. (2017). An analysis of student's speaking anxiety and its effect on speaking performance. Indonesian Journal of English Language Teaching and Applied Linguistics, 1(2), 143-152.

Watson, P. (1973, October 7). What people usually fear. Sunday Times, London, p. 9

Weismann, K. M., VanHorn, S. B., \& Paxman, C G. (2018). Best practices for retaining public speaking students. Journal of Communication Pedagogy, 1, 109-114. https:// 
doi.org/10.31446/JCP.2018.18

Workforce Institute at Kronos. (2019). Meet Gen Z. The next generation is here: Hopeful, anxious, hardworking, and searching for inspiration [PDF]. Retrieved from https://workforceinstitute.org/wp-content/uploads/2019/05/Meet-Gen-Z-HopefulAnxious-Hardworking-and-Searching-for-Inspiration.pdf 